\title{
Application of Gold Nanoparticles and Nano-Diamond Modified Electrode for Hemoglobin Electrochemistry
}

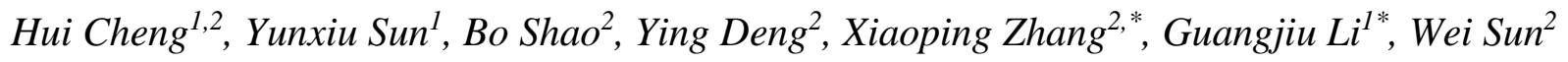 \\ ${ }^{1}$ Key Laboratory of Optic-electric Sensing and Analytical Chemistry for Life Science of Ministry of \\ Education, Shandong Key Laboratory of Biochemical Analysis, College of Chemistry and Molecular \\ Engineering, Qingdao University of Science and Technology, Qingdao 266042, P R China \\ ${ }^{2}$ Key Laboratory of Laser Technology and Optoelectronic Functional Materials of Hainan Province, \\ College of Chemistry and Chemical Engineering, Hainan Normal University, Haikou 571158, P R \\ China \\ *E-mail: 254787885@qq.com and 1gjqust@126.com
}

doi: $10.20964 / 2020.11 .15$

Received: 25 June 2020 / Accepted: 13 August 2020 / Published: 30 September 2020

\begin{abstract}
In this paper nano-diamond (ND) decorated carbon ionic liquid electrode (CILE) was constructed by drop-casting, which was further modified by electrodeposited gold nanoparticles (AuNPs), hemoglobin $(\mathrm{Hb})$ and Nafion orderly to obtain an electrochemical biosensor (Nafion/Hb/AuNPs/ND/CILE). The morphology of AuNPs/ND composite was checked by scanning electron microscopy. A pair of redox peaks of $\mathrm{Hb}$ on the modified electrode with good reversibility and symmetry appeared in cyclic voltammograms. The effects of $\mathrm{pH}$ and scan rate on $\mathrm{Hb}$ electrochemistry were further investigated to calculate the electrochemical parameters. The $\mathrm{Hb}$ based biosensor showed excellent electrocatalytic ability to the reduction of various substrates such as sodium nitrite, trichloroacetic acid and potassium bromate with the detection range from 0.07 to $2.60 \mathrm{mmol} \mathrm{L}^{-1}, 1.00$ to $500.00 \mathrm{mmol} \mathrm{L}^{-1}$ and 0.35 to $12.00 \mathrm{mmol} \mathrm{L}^{-1}$, respectively. Nafion/Hb/AuNPs/ND/CILE showed good reproducibility and stability, which was applied to the analysis $\mathrm{KBrO}_{3}$ content in real sea water samples.
\end{abstract}

Keywords: Gold nanoparticle; Nano-diamond; Electrochemistry; Carbon ionic liquid electrode; Hemoglobin.

\section{$\underline{\text { FULL TEXT }}$}

(C) 2020 The Authors. Published by ESG (www.electrochemsci.org). This article is an open access article distributed under the terms and conditions of the Creative Commons Attribution license (http://creativecommons.org/licenses/by/4.0/). 